\title{
Synthesis of Nickel-Encapsulated Carbon Nanocapsules and Cup-Stacked-Type Carbon Nanotubes via Nickel-Doped Fullerene Nanowhiskers
}

\author{
Tokushi Kizuka, ${ }^{1}$ Kun'ichi Miyazawa, ${ }^{2}$ and Akira Akagawa ${ }^{1}$ \\ ${ }^{1}$ Institute of Materials Science, Graduate School of Pure and Applied Sciences, University of Tsukuba, Tsukuba, \\ Ibaraki 305-8753, Japan \\ ${ }^{2}$ Fullerene Engineering Group, Materials Processing Unit, National Institute for Materials Science, Namiki, Tsukuba, \\ Ibaraki 305-0044, Japan \\ Correspondence should be addressed to Tokushi Kizuka, kizuka@ims.tsukuba.ac.jp
}

Received 12 July 2011; Revised 25 September 2011; Accepted 26 September 2011

Academic Editor: Zheng Hu

Copyright (๑) 2012 Tokushi Kizuka et al. This is an open access article distributed under the Creative Commons Attribution License, which permits unrestricted use, distribution, and reproduction in any medium, provided the original work is properly cited.

Nickel- $\left(\mathrm{Ni}\right.$ ) doped $\mathrm{C}_{60}$ nanowhiskers (NWs) were synthesized by a liquid-liquid interfacial precipitation method using a $\mathrm{C}_{60}-$ saturated toluene solution and isopropanol with $\mathrm{Ni}$ nitrate hexahydrate $\mathrm{Ni}\left(\mathrm{NO}_{3}\right)_{2} \cdot 6 \mathrm{H}_{2} \mathrm{O}$. By varying the heating temperature of Ni-doped $\mathrm{C}_{60} \mathrm{NWs}$, two types of one-dimensional carbon nanostructures were produced. By heating the NWs at 973 and $1173 \mathrm{~K}$, carbon nanocapsules (CNCs) that encapsulated Ni nanoparticles were produced. The Ni-encapsulated CNCs joined one dimensionally to form chain structures. Upon heating the NWs to $1373 \mathrm{~K}$, cup-stacked-type carbon nanotubes were synthesized.

\section{Introduction}

Crystals of fullerene molecules have been synthesized by precipitation methods [1-13]. Such fullerene crystals show various morphologies, that is, plates, films, and rods, and the morphology can be controlled by varying the precipitation conditions. By using a liquid-liquid interfacial precipitation (LLIP) method, Miyazawa et al. have produced fullerene nanowhiskers (NWs) and nanotubes with high length-todiameter aspect ratios [14-17]. By heating fullerene NWs, carbon nanocapsules (CNCs) are produced [18-22]. Using the LLIP method, Miyazawa et al. also found that fullerene NWs incorporate metal nanoparticles using $\mathrm{C}_{60}$ derivatives or metal nitrate hydrates in solutions [23-26]. It is expected that the alloying of metals and CNCs can be performed using metal-doped fullerene NWs. In this study, metal-CNC structures were produced by the heating nickel- $(\mathrm{Ni})$ doped $\mathrm{C}_{60}$ NWs which were synthesized by the LLIP method.

\section{Method}

$\mathrm{C}_{60}$ powders were dissolved in toluene to prepare a $\mathrm{C}_{60}$ saturated solution with a solubility of $2.8 \mathrm{~g} / \mathrm{L}$. Ni nitrate hexahydrate $\left[\mathrm{Ni}\left(\mathrm{NO}_{3}\right)_{2} \cdot 6 \mathrm{H}_{2} \mathrm{O}\right]$ was dissolved in 2-propanol with concentrations of $0.01 \mathrm{M}$ and $0.68 \mathrm{M}$ (hereafter labeled as specimens $A$ and $B$, resp.). The $\mathrm{C}_{60}$ toluene solution was poured into a glass vial, and the 2-propanol was then added to form a liquid-liquid interface. After the vial was maintained at $278 \mathrm{~K}$ for one week, the solution was filtered to extract precipitates. The precipitates were dried and heated in high vacuum at 973,1173 , and $1323 \mathrm{~K}$ for $1 \mathrm{~h}$. Next, the specimens were dispersed on microgrids and observed by transmission electron microscopy (TEM). Thermogravimetric analyses (TGA) and differential thermal analyses (DTA) of the specimens were performed in a nitrogen flow.

\section{Results and Discussion}

Figure 1(a) shows a bright-field image of an as-precipitated $\mathrm{Ni}$-doped $\mathrm{C}_{60} \mathrm{NW}$ in specimen $\mathrm{A}$. The diameter of this NW is $740 \mathrm{~nm}$. The surfaces of the Ni-doped NWs were porous, as shown in Figure 1(b). Figure 2(a) shows a brightfield image of an as-precipitated $\mathrm{Ni}$-doped $\mathrm{C}_{60} \mathrm{NW}$ in specimen B. The diameter of this NW is $240 \mathrm{~nm}$. The NWs showed undulating surfaces. Ni particles with a face-centered 


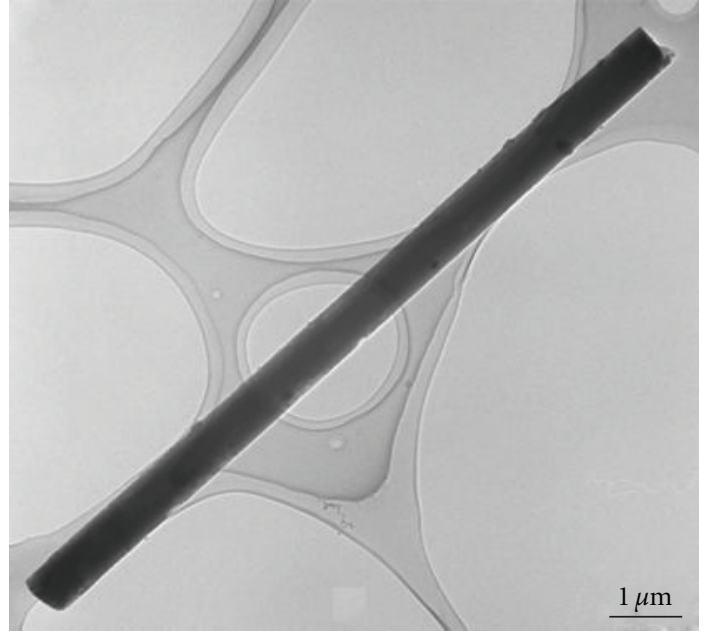

(a)

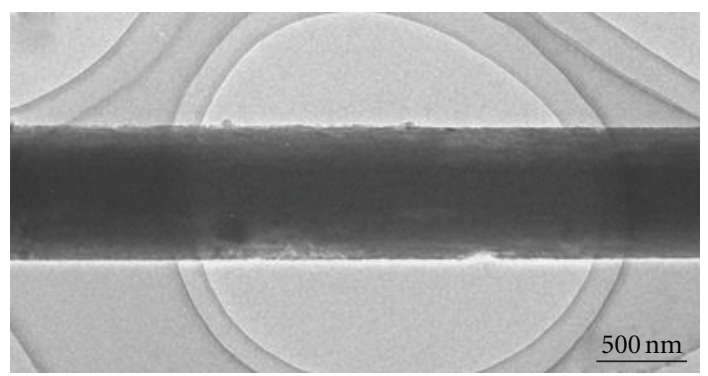

(b)

Figure 1: (a) Bright-field image of Ni-doped $\mathrm{C}_{60}$ nanowhiskers synthesized using isopropyl alcohol with concentration of $0.01 \mathrm{M}$ $\mathrm{Ni}\left(\mathrm{NO}_{3}\right)_{2} \cdot 6 \mathrm{H}_{2} \mathrm{O}$. (b) Enlarged image of (a).

cubic structure were observed in the NWs, as shown in Figure 2(b).

The surfaces of the Ni-doped NWs in both specimens $\mathrm{A}$ and $\mathrm{B}$ were rough. The roughness increases with the $\mathrm{Ni}\left(\mathrm{NO}_{3}\right)_{2} \cdot 6 \mathrm{H}_{2} \mathrm{O}$ concentration. Pure $\mathrm{C}_{60}$ NWs are surrounded by planar surfaces [14-17]. Thus, we attribute the rough surfaces of the as-precipitated $\mathrm{Ni}$-doped $\mathrm{NWs}$ to the addition of $\mathrm{Ni}\left(\mathrm{NO}_{3}\right)_{2} \cdot 6 \mathrm{H}_{2} \mathrm{O}$ in 2-propanol. In particular, $\mathrm{Ni}$ particles were observed in the dents of Ni-doped NWs, implying that the crystal growth of the NWs was inhibited by the Ni particles. This is similar to the crystal growth of $\mathrm{C}_{60}$-derivative NWs [23-25].

Figure 3 shows TGA and DTA curves of the Ni-doped NWs in specimen $A$ and $\mathrm{C}_{60}$ bulk crystals. For $\mathrm{C}_{60}$ bulk crystals, the DTA curve starts to decrease around $773 \mathrm{~K}$. On the other hand, no change is observed in the TGA curve around this temperature. This shows that the mass of the specimen remained unchanged, whereas the structure changed. The transformation from a crystalline to an amorphous configuration of $\mathrm{C}_{60}$ molecules starts at this temperature [27]. Around $1173 \mathrm{~K}$, the TGA curve decreases, and a downward peak is observed in the DTA curve, which shows that an endothermic reaction occurred. Furthermore, it has been reported that sublimation of $\mathrm{C}_{60}$ molecules takes place at this temperature [27]. On the other hand,

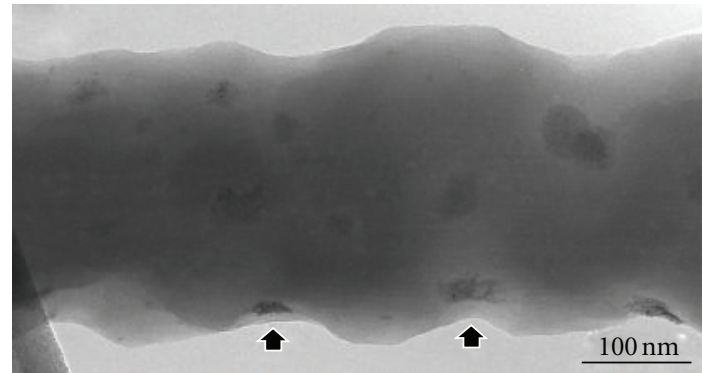

(a)

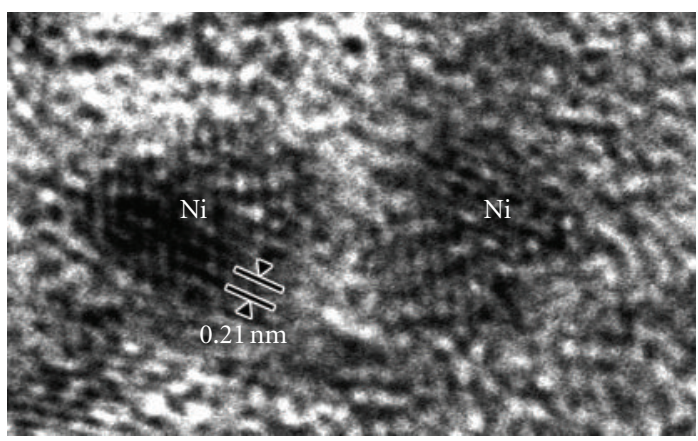

(b)

Figure 2: (a) Bright-field images of Ni-doped $\mathrm{C}_{60}$ nanowhiskers synthesized using isopropyl alcohol with concentration of $0.68 \mathrm{M}$ $\mathrm{Ni}\left(\mathrm{NO}_{3}\right)_{2} \cdot 6 \mathrm{H}_{2} \mathrm{O}$. The arrows indicate $\mathrm{Ni}$ particles in dents. (b) High-resolution image of Ni particles in the NW in (a).

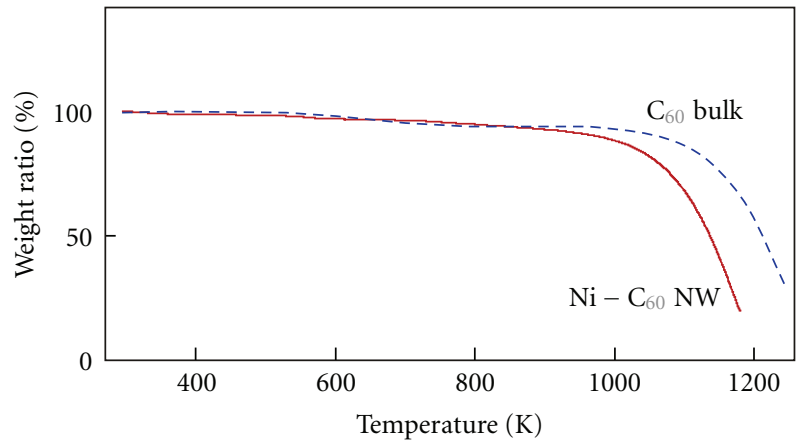

(a)

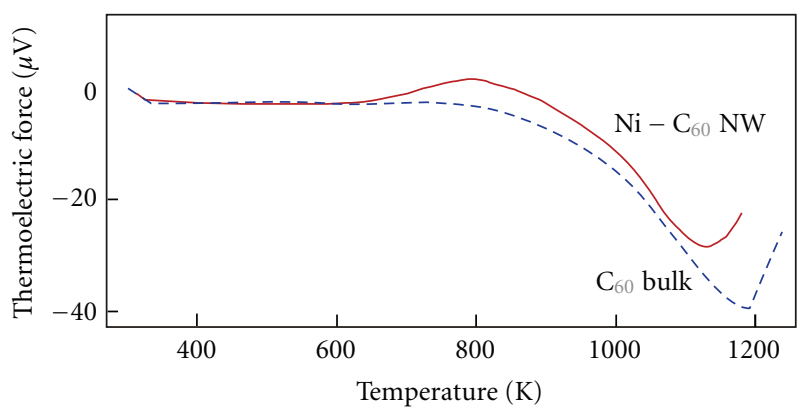

(b)

Figure 3: (a) Thermogravimetric analysis curves and (b) differential thermal analysis curves of $\mathrm{Ni}$-doped nanowhiskers (specimen $\mathrm{A}$, solid lines) and pure $\mathrm{C}_{60}$ bulk (broken lines) in nitrogen flow. 


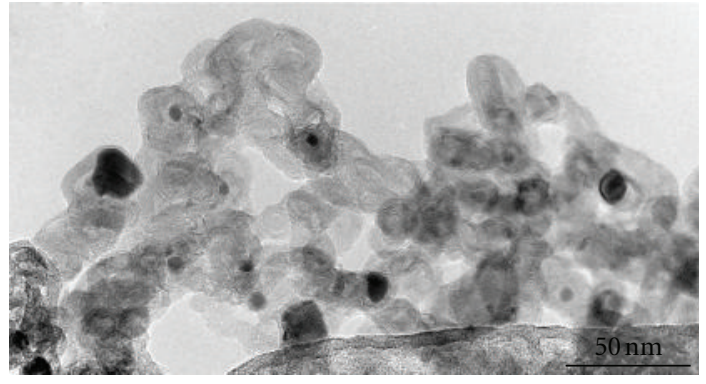

(a)

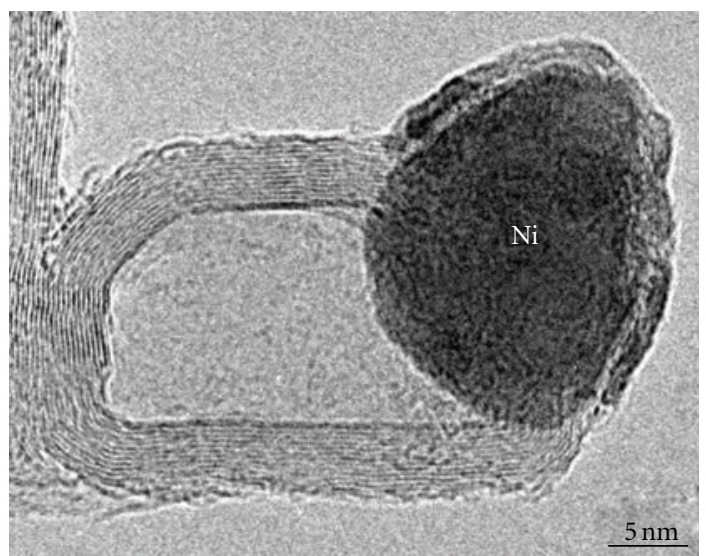

(b)

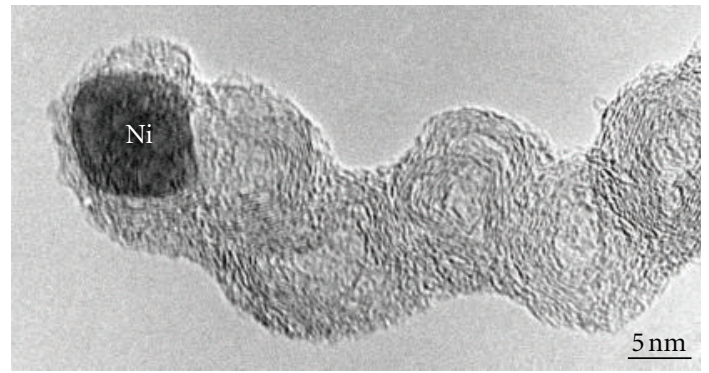

(c)

FIGURE 4: (a) Bright-field images of Ni-encapsulated carbon nanocapsules prepared by heating Ni-doped $\mathrm{C}_{60}$ nanowhiskers (specimen A) at $973 \mathrm{~K}$. (b) High-resolution image of Ni-encapsulated carbon nanocapsule. (c) High-resolution image of chain of Niencapsulated carbon nanocapsules.

for the Ni-doped NWs, an upward peak was observed in the DTA curve around $773 \mathrm{~K}$, which corresponds to an exothermic reaction. No change is observed in the TGA curve around this temperature. TEM observations showed that grain coarsening of Ni particles started near this temperature. This TEM result suggests that the upward peak around $773 \mathrm{~K}$ was caused by the grain coarsening of Ni particles.

Around $1123 \mathrm{~K}$, the TGA curve decreases and the DTA curve shows a downward peak. This implies that the sublimation of $\mathrm{C}_{60}$ molecules occurred, as similarly observed in $\mathrm{C}_{60}$ bulk crystals. Note that the sublimation temperature of $\mathrm{C}_{60}$ molecules in the $\mathrm{Ni}$-doped NWs is approximately $50 \mathrm{~K}$ lower than that in the $\mathrm{C}_{60}$ bulk crystals. From this result, we

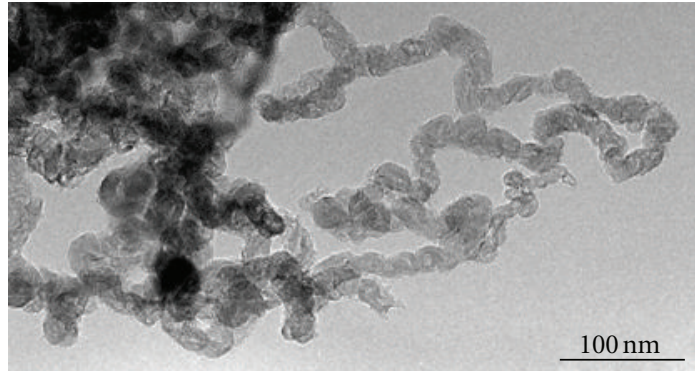

(a)

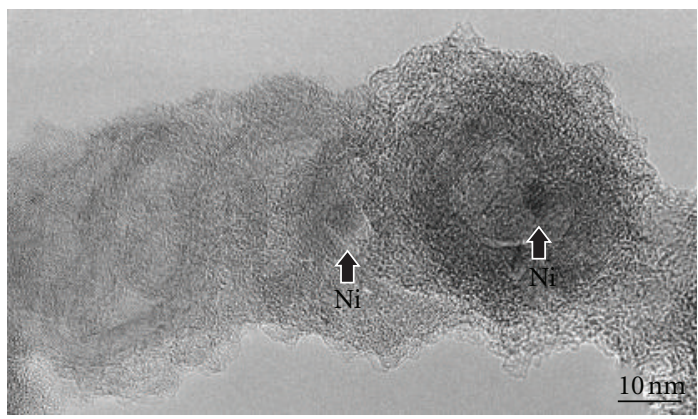

(b)

FIgURE 5: (a) Bright-field images of Ni-encapsulated carbon nanocapsules prepared by heating Ni-doped $\mathrm{C}_{60}$ nanowhiskers (specimen B) at $1173 \mathrm{~K}$. The nanocapsules form chain structures. (b) High-resolution image of the chain of Ni-encapsulated carbon nanocapsules.

infer that Ni particles act as catalysts for the weakening of intermolecular $\mathrm{C}_{60}$ molecular bonds.

On the basis of the results of TGA and DTA, we heated the specimens to temperatures higher than $973 \mathrm{~K}$ and observed them by TEM. Figures $4(\mathrm{a})$ and $4(\mathrm{~b})$ show bright-field and high-resolution images of specimen A after heating at $973 \mathrm{~K}$, respectively. Ni-encapsulated CNCs are formed by this heat treatment. The diameter of the CNCs ranged from 12 to $51 \mathrm{~nm}$. The diameter of the encapsulated $\mathrm{Ni}$ particles ranged from 8 to $33 \mathrm{~nm}$. A portion of the CNCs aligned one dimensionally to form chain structures, as shown in Figure 4(c). Such chain structures have also been produced by arc discharge $[28,29]$. As shown in Figure 4(b), Ni particles were attached on the tips of the chains, indicating that the chain structures were produced by the cycles of the precipitation of graphene shells around $\mathrm{Ni}$ particles and the movement of the Ni particles. Note that in Figure 4(b), the Ni particle protrudes from the center of the hollow region of the CNC. This state corresponds to the movement of the $\mathrm{Ni}$ particle from the precipitated graphene shell.

Figures 5(a) and 5(b) show bright-field and high-resolution images of specimen B after heating it at $1173 \mathrm{~K}$. Niencapsulated CNCs and their chain structures were formed. The formation rate of CNC chains in this specimen was higher than that in specimen A owing to a higher concentration of Ni particles.

By heating Ni-doped $\mathrm{C}_{60} \mathrm{NWs}$ in specimen B to $1323 \mathrm{~K}$, cup-stacked-type carbon nanotubes (CNTs) were produced, as shown in Figure 6. Ni particles were attached to the tip 


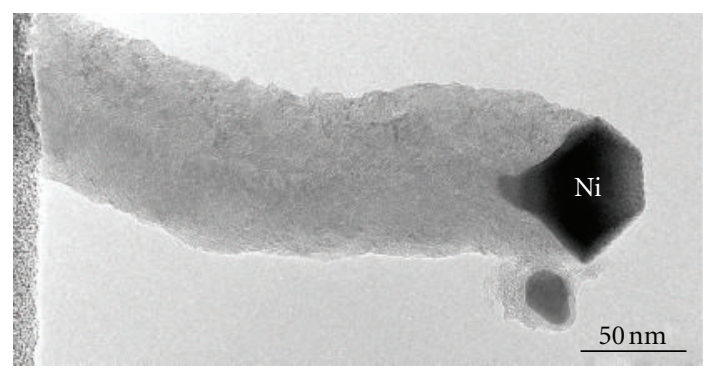

(a)

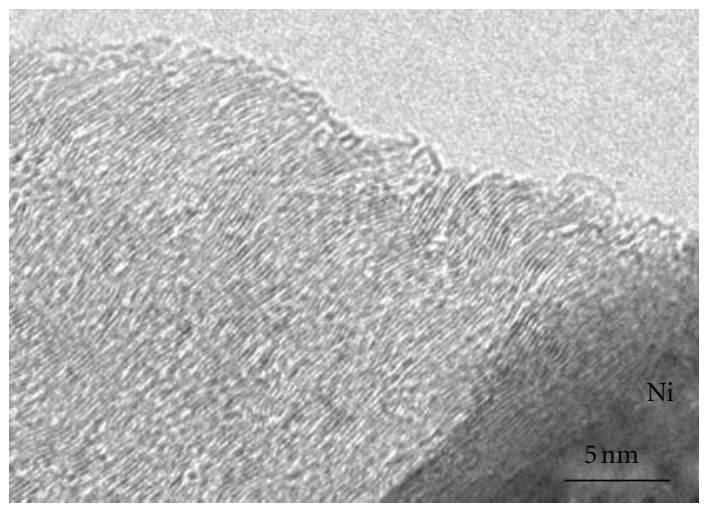

(b)

FIGURE 6: (a) Cup-stacked-type carbon nanotube synthesized by heating Ni-doped $\mathrm{C}_{60}$ nanowhiskers (specimen $\mathrm{B}$ ) at $1323 \mathrm{~K}$. (b) High-resolution image of the cup-stacked-type carbon nanotube depicted in (a).

of CNTs, and the graphene layers were aligned parallel to the surfaces of $\mathrm{Ni}$ particles. Thus, CNTs were produced by the continuous precipitation of graphene cones and the continuous movement of $\mathrm{Ni}$ particles. However, for $\mathrm{CNC}$ formation, the movement of $\mathrm{Ni}$ particles and the precipitation of graphene shells are intermittent.

In this experiment, cup-stacked-type CNTs were produced at the highest temperature $(1373 \mathrm{~K})$. As observed in Figures 4(b) and 5(a), the Ni particles in the specimens heated at temperatures lower than $1173 \mathrm{~K}$ formed spherical shapes, whereas $\mathrm{Ni}$ particles in the specimens heated to $1373 \mathrm{~K}$ formed clear crystal habits. At higher temperatures, the metal particles show more stable shapes surrounded by crystal planes with lower surface energies. Cup-stacked-type CNTs are formed by one-directional continuous precipitation of graphitic cones from metal particles having such clear crystal habits [30-39]. The solubility limit of carbon atoms in metals also increases at higher temperatures, and the precipitation speed increases. We infer that both the formation of crystal habits and the increase in precipitation speed promote the production of cup-stacked-type CNTs.

\section{Conclusion}

Ni-doped $\mathrm{C}_{60}$ NWs synthesized by the liquid-liquid interfacial precipitation method allow us to produce Ni-encapsulated CNCs and cup-stacked-type CNTs. In particular, the CNCs form chain structures. The two types of one-dimensional carbon nanostructures were produced using Ni-doped $\mathrm{C}_{60}$ NWs by varying heating temperature.

Other transition metals such as iron and cobalt can be doped into fullerene NWs using similar synthetic methods, and CNCs encapsulating nanoparticles of various metal elements can be produced using NWs.

\section{Acknowledgment}

This study was partly supported by Grants-in-Aid from the Ministry of Education, Culture, Sport, Science, and Technology, Japan (nos. 22310065 and 23651127).

\section{References}

[1] W. Krätschmer, L. D. Lamb, K. Fostiropoulos, and D. R. Huffman, "Solid $\mathrm{C}_{60}$ : a new form of carbon," Nature, vol. 347, no. 6291, pp. 354-358, 1990.

[2] W. I. F. David, R. M. Ibberson, J. C. Matthewman et al., "Crystal structure and bonding of ordered $\mathrm{C}_{60}$," Nature, vol. 353, no. 6340, pp. 147-149, 1991.

[3] S. J. Duclos, K. Brister, R. C. Haddon, A. R. Kortan, and F. A. Thiel, "Effects of pressure and stress on $\mathrm{C}_{60}$ fullerite to 20 GPa," Nature, vol. 351, no. 6325, pp. 380-382, 1991.

[4] P. A. Heiney, J. E. Fischer, A. R. McGhie et al., "Orientational ordering transition in solid $\mathrm{C}_{60}$," Physical Review Letters, vol. 66, no. 22, pp. 2911-2914, 1991.

[5] R. L. Meng, D. Ramirez, X. Jiang et al., "Growth of large, defect-free pure $\mathrm{C}_{60}$ single crystals," Applied Physics Letters, vol. 59, no. 26, pp. 3402-3403, 1991.

[6] W. Krakow, N. M. Rivera, R. A. Roy, R. S. Ruoff, and J. J. Cuomo, "Epitaxial growth of $\mathrm{C}_{60}$ thin films on mica," Journal of Materials Research, vol. 7, no. 4, pp. 784-787, 1992.

[7] X. D. Shi, A. R. Kortan, J. M. Williams, A. M. Kini, B. M. Savall, and P. M. Chaikin, "Sound velocity and attenuation in singlecrystal $C_{60}$," Physical Review Letters, vol. 68, no. 6, pp. 827-830, 1992.

[8] Y. Yosida, "Scanning electron microscope images of $\mathrm{C}_{60}$ whiskers," Japanese Journal of Applied Physics, Part 2, vol. 31, no. 4, pp. L505-L507, 1992.

[9] M. Haluška, H. Kuzmany, M. Vybornov, P. Rogl, and P. Fejdi, "A double-temperature-gradient technique for the growth of single-crystal fullerites from the vapor phase," Applied Physics A, vol. 56, no. 3, pp. 161-167, 1993.

[10] J. Z. Liu, J. W. Dykes, M. D. Lan, P. Klavins, R. N. Shelton, and M. M. Olmstead, "Vapor transport growth of $\mathrm{C}_{60}$ crystals," Applied Physics Letters, vol. 62, no. 5, pp. 531-532, 1993.

[11] J. L. de Boer, S. van Smaalen, V. Petricek, M. DusekP, M. A. Verheijen, and G. Meijer, "Hexagonal close-packed $\mathrm{C}_{60}$," Chemical Physics Letters, vol. 219, no. 5-6, pp. 469-472, 1994.

[12] F. Michaud, M. Barrio, S. Toscani et al., "Solid-state studies on single and decagonal crystals of $\mathrm{C}_{60}$ grown from 1,2-dichloroethane," Physical Review B, vol. 57, no. 17, pp. 10351-10358, 1998.

[13] S. Toscani, H. Allouchi, J. L. Tamarit et al., "Decagonal $\mathrm{C}_{60}$ crystals grown from $\mathrm{n}$-hexane solutions: solid-state and aging studies," Chemical Physics Letters, vol. 330, no. 5-6, pp. 491496, 2000.

[14] K. Miyazawa, A. Obayashi, and M. Kuwabara, " $\mathrm{C}_{60}$ nanowhiskers in a mixture of lead zirconate titanate sol- $\mathrm{C}_{60}$ toluene solution," Journal of the American Ceramic Society, vol. 84, no. 3-12, pp. 3037-3039, 2001.

[15] K. Miyazawa, " $\mathrm{C}_{70}$ nanowhiskers fabricated by forming liquid/liquid interfaces in the systems of toluene solution of 
$\mathrm{C}_{70}$ and isopropy/alcohol," Journal of the American Ceramic Society, vol. 85, no. 5, pp. 1297-1299, 2002.

[16] K. Miyazawa, Y. Kuwasaki, A. Obayashi, and M. Kuwabara, " $\mathrm{C}_{60}$ nanowhiskers formed by the liquid-liquid interfacial precipitation method," Journal of Materials Research, vol. 17, no. 1, pp. 83-88, 2002.

[17] K. Miyazawa, K. Hamamoto, S. Nagata, and T. Suga, "Structural investigation of the $\mathrm{C}_{60} / \mathrm{C}_{70}$ whiskers fabricated by forming liquid-liquid interfaces of toluene with dissolved $\mathrm{C}_{60} / \mathrm{C}_{70}$ and isopropyl alcohol," Journal of Materials Research, vol. 18, no. 5, pp. 1096-1103, 2003.

[18] K. Asaka, R. Kato, Y. Maezono, R. Yoshizaki, K. Miyazawa, and T. Kizuka, "Light-emitting filaments composed of nanometersized carbon hollow capsules," Applied Physics Letters, vol. 88, no. 5, Article ID 051914, pp. 1-3, 2006.

[19] K. Asaka, R. Kato, K. Miyazawa, and T. Kizuka, "Deformation of multiwalled nanometer-sized carbon capsules," Applied Physics Letters, vol. 89, no. 19, Article ID 191914, 2006.

[20] K. Asaka, R. Kato, R. Yoshizaki, K. Miyazawa, and T. Kizuka, "Conductance of carbon nanocapsule junctions," Physical Review B, vol. 76, no. 11, Article ID 113404, 2007.

[21] T. Kizuka, R. Kato, and K. Miyazawa, "Structure of hollow carbon nanocapsules synthesized by resistive heating," Carbon, vol. 47, no. 1, pp. 138-144, 2009.

[22] T. Kizuka, R. Kato, and K. Miyazawa, "Surface breakdown dynamics of carbon nanocapsules," Nanotechnology, vol. 20, no. 10, Article ID 105205, 2009.

[23] K. Miyazawa, T. Mashino, and T. Suga, "Structural characterization of the $\mathrm{C}_{60}\left[\mathrm{C}\left(\mathrm{COOC}_{2} \mathrm{H}_{5}\right)_{2}\right]$ whiskers prepared by the liquid-liquid interfacial precipitation method," Journal of Materials Research, vol. 18, no. 11, pp. 2730-2735, 2003.

[24] K. Miyazawa and T. Suga, "Transmission electron microscopy investigation of fullerene nanowhiskers and needle-like precipitates formed by using $\mathrm{C}_{60}$ and $\left(\eta^{2}-\mathrm{C}_{60}\right) \mathrm{Pt}\left(\mathrm{PPh}_{3}\right)_{2}$," Journal of Materials Research, vol. 19, no. 8, pp. 2410-2414, 2004.

[25] K. Miyazawa and T. Suga, "Transmission electron microscopy investigation of tubular and capsular needlelike crystals of $\mathrm{C}_{60}$ produced by the liquid-liquid interfacial precipitation method," Journal of Materials Research, vol. 19, no. 11, pp. 3145-3148, 2004.

[26] M. Sathish, K. Miyazawa, and T. Sasaki, "Preparation and characterization of $\mathrm{Ni}$ incorporated fullerene nanowhiskers," Diamond and Related Materials, vol. 17, no. 4-5, pp. 571-575, 2008.

[27] V. Z. Mordkovich, A. G. Umnov, T. Inoshita, and M. Endo, "Observation of multiwall fullerenes in thermally treated laser pyrolysis carbon blacks," Carbon, vol. 37, no. 11, pp. 1855$1858,1999$.

[28] Y. Saito, T. Yoshikawa, M. Okuda et al., "Carbon nanocapsules encaging metals and carbides," Journal of Physics and Chemistry of Solids, vol. 54, no. 12, pp. 1849-1860, 1993.

[29] Y. Saito, "Nanoparticles and filled nanocapsules," Carbon, vol. 33, no. 7, pp. 979-988, 1995.

[30] A. T. Balaban, D. J. Klein, and X. Liu, “Graphitic cones," Carbon, vol. 32, no. 2, pp. 357-359, 1994.

[31] H. Terrones, "Curved graphite and its mathematical transformations," Journal of Mathematical Chemistry, vol. 15, no. 1, pp. 143-156, 1994.

[32] H. Terrones, T. Hayashi, M. Muñoz-Navia et al., "Graphitic cones in palladium catalysed carbon nanofibres," Chemical Physics Letters, vol. 343, no. 3-4, pp. 241-250, 2001.

[33] B. O. Boskovic, V. Stolojan, R. U. A. Khan, S. Haq, and S. R. P. Silva, "Large-area synthesis of carbon nanofibres at room temperature," Nature Materials, vol. 1, no. 3, pp. 165-168, 2002.
[34] M. Endo, Y. A. Kim, T. Hayashi et al., "Structural characterization of cup-stacked-type nanofibers with an entirely hollow core," Applied Physics Letters, vol. 80, no. 7, pp. 1267-1269, 2002.

[35] Y. A. Kim, T. Hayashi, Y. Fukai, M. Endo, T. Yanagisawa, and M. S. Dresselhaus, "Effect of ball milling on morphology of cup-stacked carbon nanotubes," Chemical Physics Letters, vol. 355, no. 3-4, pp. 279-284, 2002.

[36] M. Endo, Y. A. Kim, M. Ezaka et al., "Selective and efficient impregnation of metal nanoparticles on cup-stacked-type carbon nanofibers," Nano Letters, vol. 3, no. 6, pp. 723-726, 2003.

[37] C. Kim, Y. J. Kim, Y. A. Kim et al., "High performance of cupstacked-type carbon nanotubes as a Pt-Ru catalyst support for fuel cell applications," Journal of Applied Physics, vol. 96, no. 10, pp. 5903-5905, 2004.

[38] K. Saito, M. Ohtani, and S. Fukuzumi, "Electron-transfer reduction of cup-stacked carbon nanotubes affording cupshaped carbons with controlled diameter and size," Journal of the American Chemical Society, vol. 128, no. 44, pp. 1421614217, 2006.

[39] Q. Liu, W. Ren, Z. G. Chen et al., "Semiconducting properties of cup-stacked carbon nanotubes," Carbon, vol. 47, no. 3, pp. 731-736, 2009. 

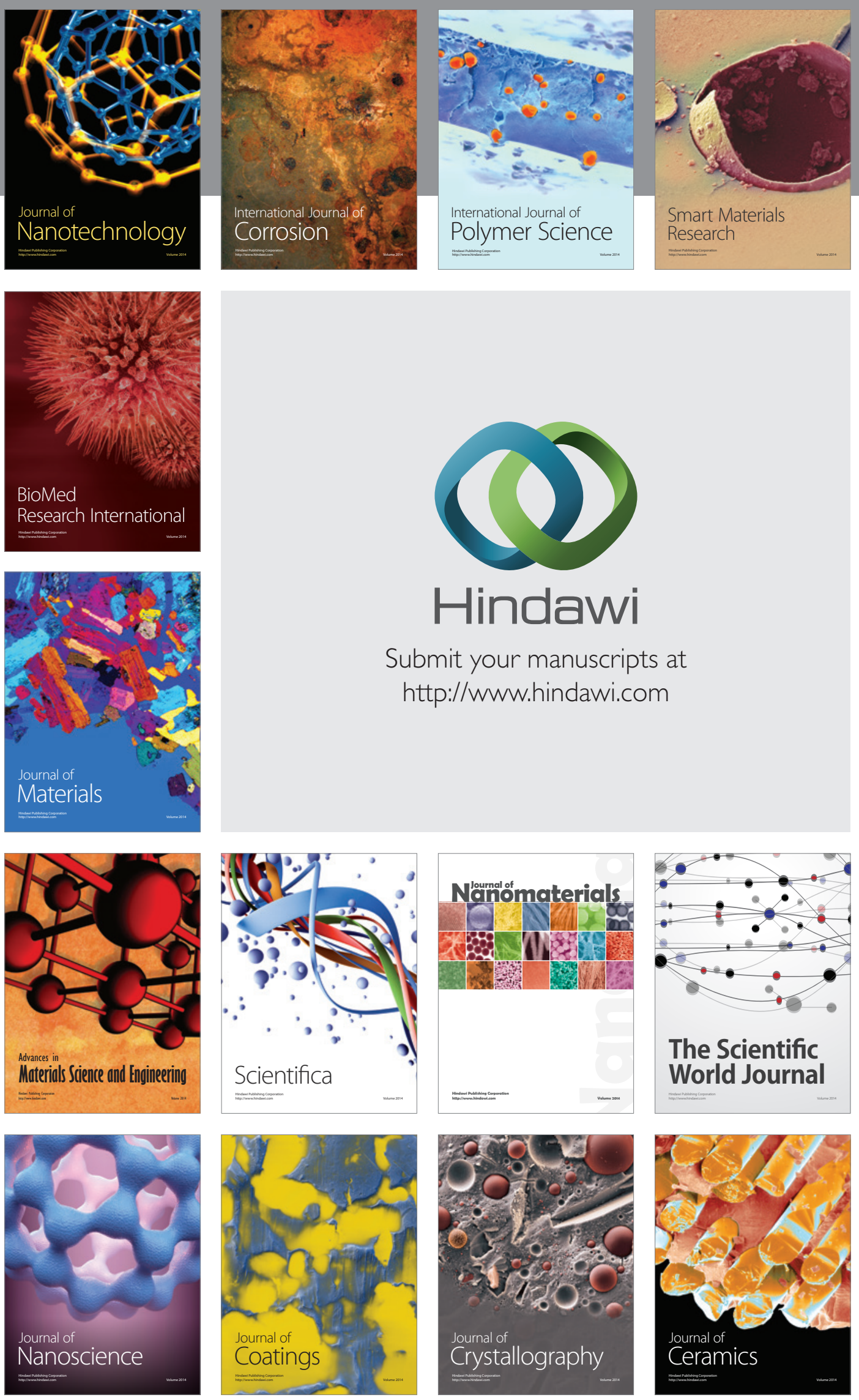

The Scientific World Journal

Submit your manuscripts at

http://www.hindawi.com

\section{World Journal}

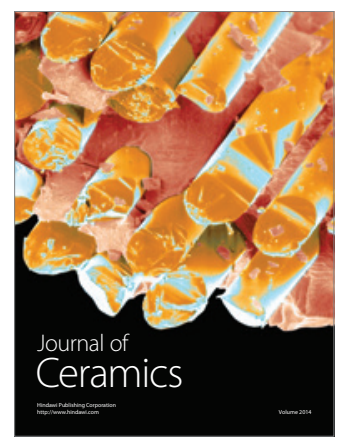

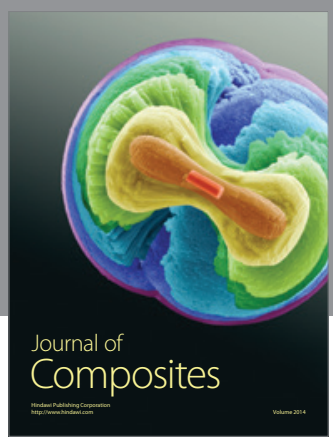
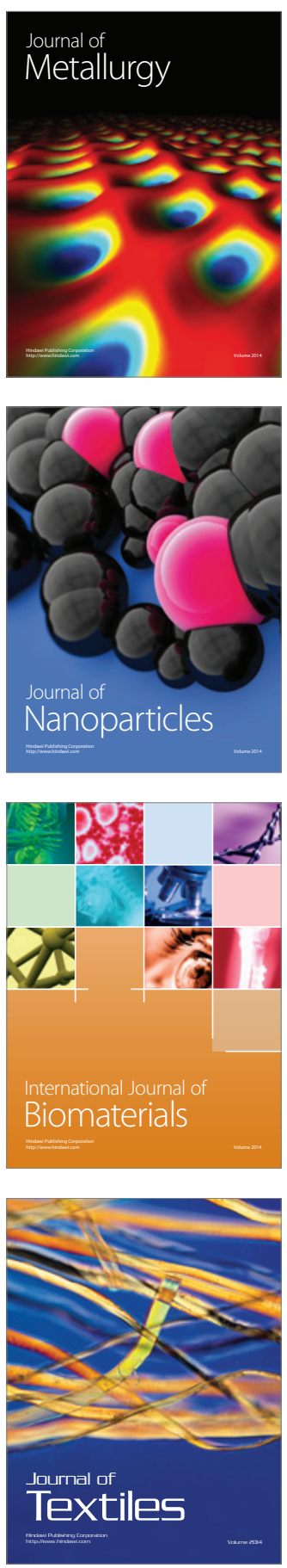